Proc. of the X Int. Conf. - Ion Implantation and other Applications of Ions and Electrons, Kazimierz Dolny 2014

\title{
Application of HPLC-MS with Electrospray Ionization for the Qualitative and Quantitative Analysis of Antibiotics in Pharmaceutical Formulation
}

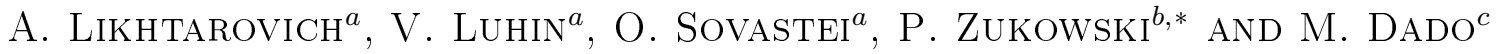 \\ ${ }^{a}$ Belarusian State University of Technology, 13a, Sverdlova Str., 220050 Minsk, Republic of Belarus \\ ${ }^{b}$ Lublin University of Technology, Nadbystrzycka 38a, 20-618 Lublin, Poland \\ ${ }^{c}$ University of Zilina, 1, Univerzitná Str., 01026 Žilina, Slovakia
}

\begin{abstract}
This study describes the application of electrospray ionization mass spectrometry in order to identify ten antibiotics (macrolides, penicillins, aminoglycosides). An optimum procedure was developed for determination of antibiotics of different grade. Positive ion spectra of most antibiotics are higher in intensity including an $[\mathrm{M}+\mathrm{H}]^{+}$ion and produce less fragmentation and are more informative compared to the negative ion spectra. The group of antibiotics exhibits the same characteristic fragmentation. The data base was developed for identification of antibiotics comparing of their molecular and fragment ions. The results of the study showed that the method with electrospray ionization is simple and quick which is useful in the routine determination of antibiotics and in their pharmaceutical dosage forms.
\end{abstract}

DOI: 10.12693/APhysPolA.128.901

PACS: $32.10 . \mathrm{Bi}, 33.15 . \mathrm{Ta}, 82.80 .-\mathrm{d}$

\section{Introduction}

High performance liquid chromatography-mass spectrometry (HPLC-MS) is an invaluable analytical tool that is used in major areas of the drug discovery process in many key steps and is characterized by high sensitivity and specificity. A number of published papers have been devoted to describing many various approaches to development and improvement of this method. For this reason MS is accepted in industrial, routine laboratory practice and academic research because of its economical and diagnostic benefits.

Mass-spectroscopy is an effective technique for reliable identification of compounds. The electrospray ionization (ESI) is a soft ionization method most commonly used when dealing with complicated structures. In ESI an effluent from HPLC is sprayed across a high electrical potential from a metal capillary, positioned in front of the counter electrode. Very high electric field intensity is created between the end of the capillarity tip and the electrode. This electric field leads to a partial separation of positive and negative ions of the electrolyte. Evaporation of the mobile phase is enhanced with a stream of heated nitrogen gas. As evaporation occurs, the ions are transformed from a dissolved phase into a gaseous phase immediately prior to introduction into a vacuum region of the mass spectrometer. The generated gas-phase ions are electrostatically extracted into a mass analyzer and separated according to their mass-to-charge ratio and finally detected [1].

\footnotetext{
* corresponding author; e-mail: pawel@elektron.pol.lublin.pl
}

ESI is suited for highly to moderately polar and ionic analytes containing acidic and basic functional groups. Positive ionization consist in protonation and is suitable for the compounds containing basic functional groups, typically producing $[\mathrm{M}+\mathrm{H}]^{+},[\mathrm{M}+\mathrm{Na}]^{+}$ and $[\mathrm{M}+\mathrm{K}]^{+}$ions. Negative ionization consists in deprotonation and therefore is suitable for the compounds containing an acidic functional group, typically producing $[\mathrm{M}-\mathrm{H}]^{-}$ions. Most antibiotics have both types of functional groups and ionize in positive as well as negative modes [2,3]. Furthermore, many antibiotics are nonvolatile with high molecular weights and they respond well in ESI which makes HPLC-MS the technique of choice for their analysis [4].

Thus the purpose of this study was to develop a method for the identification of antibiotics in pharmaceutical formulation by HPLC-MS, understanding the rules for fragmentation of antibiotics after ionization in an ESI source and to develop library.

\section{Experimental details and results}

The most widely used ten substances of antibiotics were prepared by accurately weighing $1 \mathrm{mg}$ and $0.1 \mathrm{mg}$ and dissolving each in $1 \mathrm{~mL}$ acetonitrile (Fisher Scientific, UK) or methanol (Merck, Germany) to achieve optimum parameters and determine characteristic ions. Organic solvents were of HPLC-grade. The antibiotic solution was analyzed using the HPLC-MS spectrometer "Waters" on BDS HYPERSIL column C18 $2504.6 \mathrm{~mm}$, with the diode-array PDA 996 and a mass-detector Micromass ZQ 2000, equipped with ESI. The ESI interface was used in positive and negative modes.

Since antibiotics have both carboxylic and amino functionality in its chemical structure, the possibility of mass spectrometric detection under positive as well as negative 
ion modes was first estimated. The optimal mass spectrometric conditions for the detection of most analytes were achieved in the positive ion mode with the ESI interface. Besides, there was studied an effect of operating conditions on fragmentation of antibiotics and there were optimized the following ionization parameters: capillary voltage, cone voltage, extractor voltage, source temperature; cone gas flow, desolvation gas flow. The desolvation temperature was $350{ }^{\circ} \mathrm{C}$, the highest temperature facilitated desolvation of the sample, cone gas flow at $50 \mathrm{~L} \mathrm{~h}^{-1}$, capillary voltage at $3 \mathrm{kV}$. As a result of operating conditions, intensity of precursor and daughter ions change in the mass-spectrum relative to each other. The major product ions and relative abundance of the ions in the mass spectra obtained under different conditions were compared. The principle of optimization was obtained with protonated molecules $[\mathrm{M}+\mathrm{H}]^{+}$and some intensive product ions.

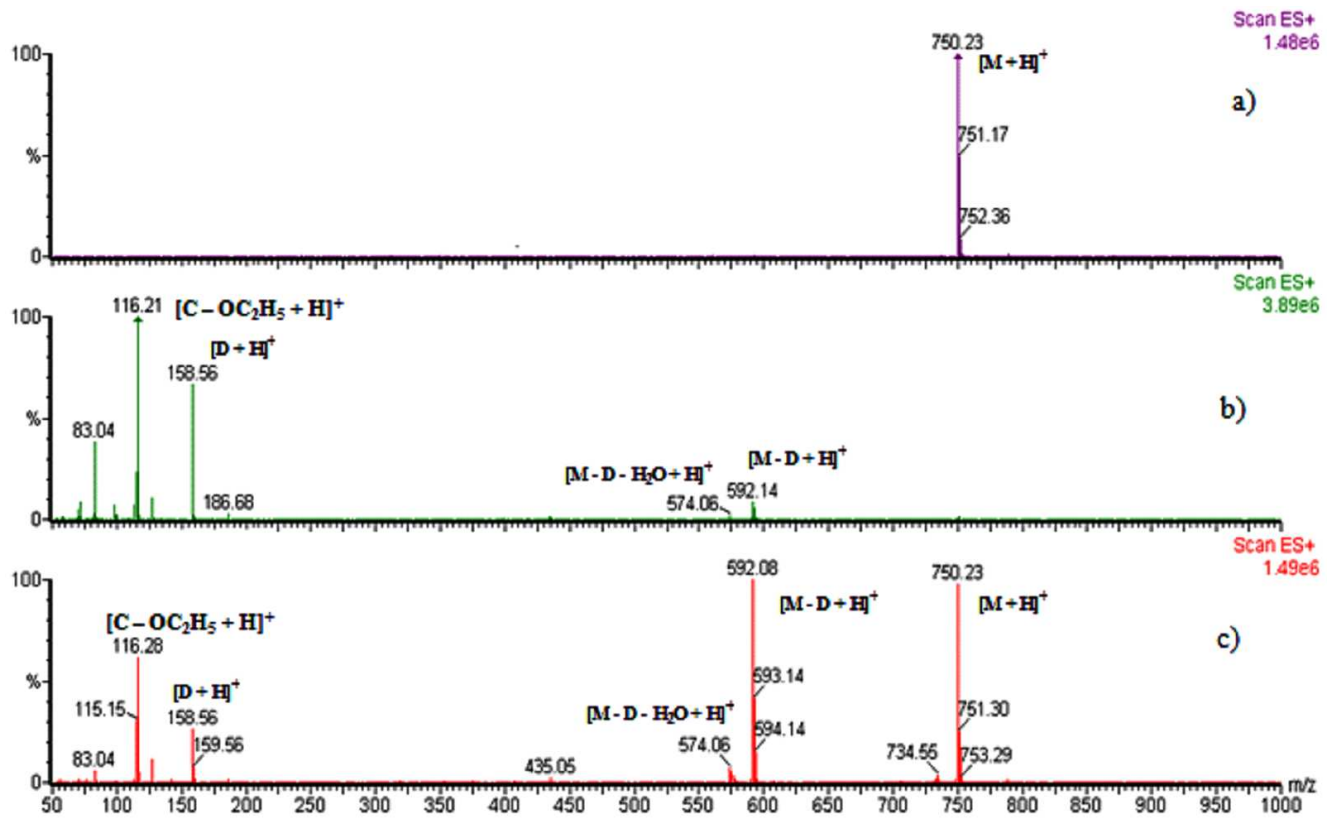

Fig. 1. Mass spectrum of azithromycin in a positive mode under different conditions.

The experimental results for the three samples were the same. Azyithromicin was used in this paper as a representative example to show the results under each condition. The mass spectrum of azithromicin is presented in Fig. 1. The maximum intensity of molecular ion without fragmentation was obtained under the following conditions: cone voltage at $20 \mathrm{~V}$, extractor voltage at $2 \mathrm{~V}$, source temperature at $100^{\circ} \mathrm{C}$, desolvation gas flow at $300 \mathrm{~L} \mathrm{~h}^{-1}$ (Fig. 1a). When the cone voltage is $60 \mathrm{~V}$, extractor voltage is $5 \mathrm{~V}$, desolvation temperature is $200^{\circ} \mathrm{C}$, source temperature is $70^{\circ} \mathrm{C}$; cone gas flow is $50 \mathrm{~L} \mathrm{~h}^{-1}$, desolvation gas flow is $150 \mathrm{~L} \mathrm{~h}^{-1}$ molecular ion is quite broken into product ions (Fig. 1b). The optimum conditions are: the cone voltage $40 \mathrm{~V}$, extractor voltage $2 \mathrm{~V}$, source temperature $100^{\circ} \mathrm{C}$; desolvation gas flow $300 \mathrm{~L} \mathrm{~h}^{-1}$ to acquire mass-spectrum including molecular and daughter ions (Fig. 1c). Removal of desosamine (D) and cladinose (C) from a molecule, then their degradation together with lactonic ring are typical of macrolides. Therefore all analytes give rise to the class-specific fragment $m / z 158 \mathrm{Da}$ and compoundspecific daughter ions $[\mathrm{M}+\mathrm{H}-158]^{+}$such as for example $m / z 590$ Da for clarithromycin and $m / z 679$ Da for roxithromycin. The direction of molecule fragmentation of azyithromicin is presented in Fig. 2.
Every mass spectrum typically includes the line of characteristic parent ion and from two to five relatively intensive daughter ions. This brings us to the conclusion that antibiotics from the same group (for example, macrolide) have some similar product ions. It can be a principle for creating library and use it for identification of unknown antibiotics.

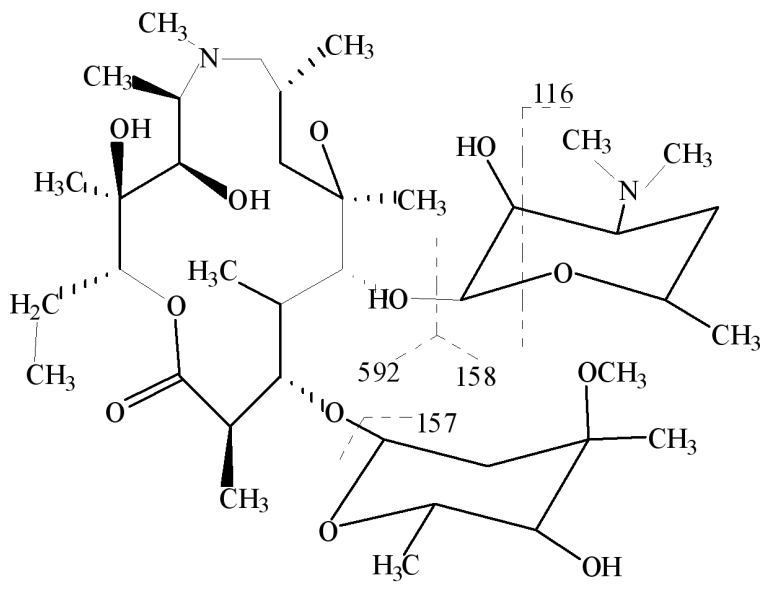

Fig. 2. Mass spectral fragmentation pathway of azithromycin. 
Characteristic precursor and product ions of some macrolides, aminoglycosides and $\beta$-lactam antibiotics.

TABLE

\begin{tabular}{|c|c|c|c|c|c|}
\hline Antibiotic & $\begin{array}{c}\text { Molecular } \\
\text { ion, } m / z[\mathrm{Da}]\end{array}$ & Product ion $1, m / z$ [Da] & Product ion $2, m / z$ [Da] & Product ion $3, m / z$ [Da] & Other ions, $m / z[\mathrm{Da}]$ \\
\hline $\begin{array}{c}\text { azithromycin } \\
\text { (positive mode) }\end{array}$ & $\begin{array}{c}750.23 \\
{[\mathrm{M}+\mathrm{H}]^{+}}\end{array}$ & $\begin{array}{c}574.11 \\
{\left[\mathrm{M}-\text { desosamine- } \mathrm{H}_{2} \mathrm{O}+\mathrm{H}\right]^{+}}\end{array}$ & $\begin{array}{c}592.08 \\
{[\mathrm{M}-\text { desosamine }+\mathrm{H}]^{+}}\end{array}$ & $\begin{array}{c}158.56 \\
{[\text { desosamine }+\mathrm{H}]^{+}}\end{array}$ & $\begin{array}{c}116.28 \\
{\left[\text { cladinose- } \mathrm{OC}_{2} \mathrm{H}_{5}+\mathrm{H}\right]^{+}}\end{array}$ \\
\hline $\begin{array}{l}\text { roxithromycin } \\
\text { (positive mode) }\end{array}$ & $\begin{array}{c}837.41 \\
{[\mathrm{M}+\mathrm{H}]^{+}} \\
859.40 \\
{[\mathrm{M}+\mathrm{Na}]^{+}}\end{array}$ & $\begin{array}{c}679.32 \\
{[\mathrm{M}-\text { desosamine }+\mathrm{H}]^{+}}\end{array}$ & 558.25 & $\begin{array}{c}158.09 \\
{[\text { desosamine }+\mathrm{H}]^{+}}\end{array}$ & $\frac{116.31}{\left[\text { cladinose- } \mathrm{OC}_{2} \mathrm{H}_{5}+\mathrm{H}\right]^{+}}$ \\
\hline $\begin{array}{c}\text { amikacin } \\
\text { (positive mode) }\end{array}$ & $\begin{array}{c}586.25 \\
{[\mathrm{M}+\mathrm{H}]^{+}}\end{array}$ & $\begin{array}{c}425.20 \\
{\left[\mathrm{M}-\mathrm{N}_{2} \mathrm{C}_{6} \mathrm{H}_{13} \mathrm{O}_{3}+\mathrm{H}\right]^{+}}\end{array}$ & $\begin{array}{c}247.17 \\
{\left[\mathrm{NC}_{6} \mathrm{H}_{12} \mathrm{O}_{4} \mathrm{O}(\mathrm{CH})_{2}+\mathrm{H}\right]^{+}}\end{array}$ & $\begin{array}{c}163.11 \\
{\left[\mathrm{NC}_{6} \mathrm{H}_{12} \mathrm{O}_{4}+\mathrm{H}\right]^{+}}\end{array}$ & $\begin{array}{c}101.75 \\
\text { [cleavage in } \\
\left.\mathrm{N}_{2} \mathrm{C}_{6} \mathrm{H}_{13} \mathrm{O}_{3}+\mathrm{H}\right]^{+}\end{array}$ \\
\hline $\begin{array}{c}\text { tobramycine } \\
\text { (positive mode) }\end{array}$ & $\begin{array}{c}468.20 \\
{[\mathrm{M}+\mathrm{H}]^{+}}\end{array}$ & $\begin{array}{c}324.17 \\
{\left[\mathrm{M}-\mathrm{N}_{2} \mathrm{C}_{6} \mathrm{H}_{12} \mathrm{O}_{2}+\mathrm{H}\right]^{+}}\end{array}$ & $\begin{array}{c}205.14 \\
{\left[\mathrm{NC}_{6} \mathrm{H}_{12} \mathrm{O}_{4} \mathrm{O}(\mathrm{CH})_{2}+\mathrm{H}\right]^{+}}\end{array}$ & $\begin{array}{c}163.11 \\
{\left[\mathrm{NC}_{6} \mathrm{H}_{12} \mathrm{O}_{4}+\mathrm{H}\right]^{+}}\end{array}$ & $\begin{array}{c}145.06 \\
\text { [cleavage in } \\
\left.\mathrm{N}_{2} \mathrm{C}_{6} \mathrm{H}_{13} \mathrm{O}_{3}+\mathrm{H}\right]^{+}\end{array}$ \\
\hline $\begin{array}{c}\text { kanamycin } \\
\text { (positive mode) }\end{array}$ & $\begin{array}{c}485.16 \\
{[\mathrm{M}+\mathrm{H}]^{+}}\end{array}$ & 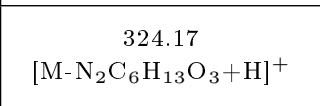 & $\begin{array}{c}205.14 \\
{\left[\mathrm{NC}_{6} \mathrm{H}_{12} \mathrm{O}_{4} \mathrm{O}(\mathrm{CH})_{2}+\mathrm{H}\right]^{+}}\end{array}$ & $\begin{array}{c}163.11 \\
{\left[\mathrm{NC}_{6} \mathrm{H}_{12} \mathrm{O}_{4}+\mathrm{H}\right]^{+}}\end{array}$ & $\begin{array}{c}101.75 \\
\text { [cleavage in } \\
\left.\mathrm{N}_{2} \mathrm{C}_{6} \mathrm{H}_{13} \mathrm{O}_{3}+\mathrm{H}\right]^{+}\end{array}$ \\
\hline $\begin{array}{c}\text { amoxicillin } \\
\text { (positive mode) }\end{array}$ & $\begin{array}{c}366.86 \\
{[\mathrm{M}+\mathrm{H}]^{+}} \\
388.80 \\
{[\mathrm{M}+\mathrm{Na}]^{+}}\end{array}$ & $\begin{array}{c}349.630 \\
{\left[\mathrm{M}-\mathrm{NH}_{3}+\mathrm{H}\right]^{+}}\end{array}$ & $\begin{array}{c}208.52 \\
{\left[\mathrm{M}-\mathrm{SNC}_{6} \mathrm{O}_{2} \mathrm{H}_{9}-\mathrm{NH}_{3}+\mathrm{H}_{2} \mathrm{O}+\mathrm{H}\right]^{+} ;} \\
160.40 \\
{\left[\mathrm{SNC}_{6} \mathrm{O}_{2} \mathrm{H}_{9}+\mathrm{H}\right]^{+}}\end{array}$ & {$\left[\begin{array}{c}114.12 \\
{\left[\mathrm{SNC}_{6} \mathrm{O}_{2} \mathrm{H}_{9}-\mathrm{COOH}+\mathrm{H}\right]^{+}}\end{array}\right.$} & $\begin{array}{c}107.16 \\
{\left[\mathrm{C}_{7} \mathrm{H}_{6} \mathrm{O}+\mathrm{H}\right]^{+}} \\
134.35\end{array}$ \\
\hline $\begin{array}{c}\text { carbenicillin } \\
\text { (positive mode) }\end{array}$ & $\begin{array}{c}379.02 \\
{[\mathrm{M}+\mathrm{H}]^{+}} \\
401.07 \\
{[\mathrm{M}+\mathrm{Na}]^{+}}\end{array}$ & $\begin{array}{c}220.06 \\
{\left[\mathrm{M}-\mathrm{SNC}_{6} \mathrm{O}_{2} \mathrm{H}_{9}+\mathrm{H}\right]^{+}}\end{array}$ & $\begin{array}{c}204.09 \\
{\left[\mathrm{C}_{6} \mathrm{H}_{5} \mathrm{CH}+\mathrm{NC}_{6} \mathrm{O}_{2} \mathrm{H}_{9}\right]^{+}}\end{array}$ & - & $\begin{array}{l}327.11 \\
301.15 \\
183.18 \\
134.90\end{array}$ \\
\hline $\begin{array}{c}\text { piperacillin } \\
\text { (negative mode) }\end{array}$ & $\begin{array}{r}516.03 \\
{[\mathrm{M}-\mathrm{H}]^{-}}\end{array}$ & $\begin{array}{c}330.04 \\
{\left[\mathrm{M}_{-} \mathrm{SNC}_{6} \mathrm{O}_{2} \mathrm{H}_{9}-\mathrm{CO}\right]^{-}}^{-}\end{array}$ & $\begin{array}{c}232.96 \\
{\left[\mathrm{SN}_{2} \mathrm{C}_{6} \mathrm{O}_{2} \mathrm{H}_{10}+\mathrm{H}_{2} \mathrm{O}-\mathrm{H}\right]^{-}}\end{array}$ & $\begin{array}{c}189.95 \\
{\left[\mathrm{C}_{6} \mathrm{H}_{5} \mathrm{~N}_{2} \mathrm{C}_{4} \mathrm{O}_{2} \mathrm{H}_{4}\right]^{-}}\end{array}$ & 99.60 \\
\hline $\begin{array}{c}\text { ampicillin } \\
\text { (negative mode) }\end{array}$ & $\begin{array}{c}302.13 \\
{\left[\mathrm{M}-\mathrm{CH}_{2} \mathrm{O}_{2}-\mathrm{H}\right]^{-}}\end{array}$ & 270.12 & 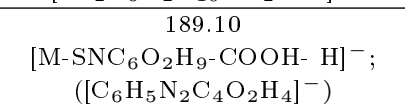 & $\begin{array}{c}113.75 \\
{\left[\mathrm{SNC}_{6} \mathrm{O}_{2} \mathrm{H}_{9}-\mathrm{COOH}-\mathrm{H}\right]^{-}}\end{array}$ & - \\
\hline
\end{tabular}

Similarly, the typical fragmentation pathway of aminoglycoside under last conditions includes cleavage of 6amino-6-desoxyglucopiranosyl $(\mathrm{m} / z 163 \mathrm{Da})$ from the precursor ion, breaking hydroxycyclohexyl and cleavage of 3-amino-3-desoxy-glucopyranosyl with or without $-\mathrm{CHCH}-$ part from hydroxycyclohexyl. So the classspecific fragment is $m / z 163 \mathrm{Da}$, the compound-specific daughter $-[\mathrm{M}+\mathrm{H}-163]^{+}$. The detailed description of this pathway is given based on tobramycine (Fig. 3). The use of ESI-MS for structural information in the detection of $\beta$-lactam antibiotics was confirmed in positive and negative modes. Mass spectra of piperacillin and ampicillin with high intensity of characteristic ions were obtained in the negative ion mode because these samples have only a carboxylic group in the chemical structure. As portrayed in Fig. 4, the daughter ion generated by ESI leads to breaking of the $\beta$-lactam ring and cleavage benzyl structure from the precursor ion.

The analytical results of single compounds of antibiotic are summarized in the Table. Additionally, the most likely fragmentation patterns are shown where plausible. They are in accordance to the mass spectra of other LCMS determinations [5-7].

The created library was successfully applied for the identification of these antibiotics. As follows from the results all the spectra could be correctly identified,

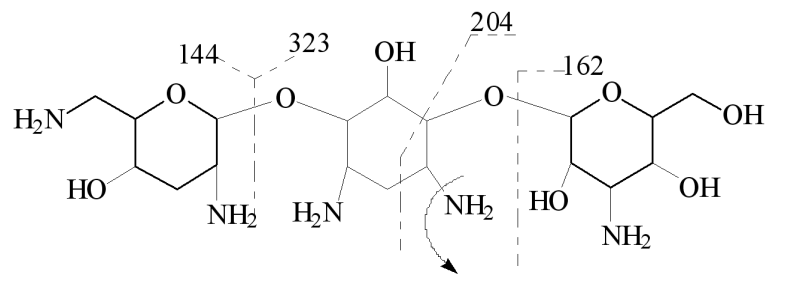

Fig. 3. Mass spectral fragmentation pathway of tobramycine.

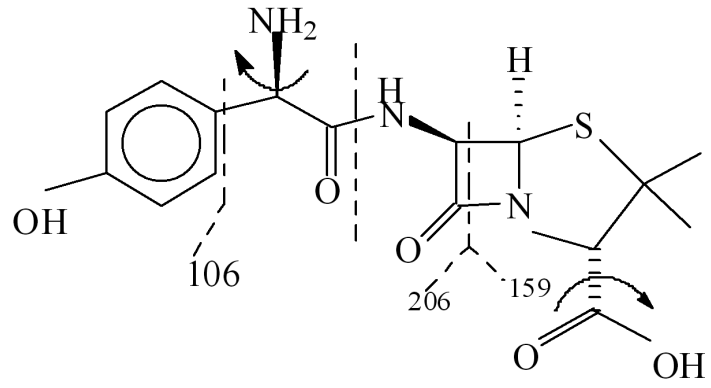

Fig. 4. Mass spectral fragmentation pathway of amoxicillin. 
but as the amount of sample decreased, the similarity between the mass spectrum from the library and the mass spectrum of analyte decreased.

\section{Conclusion}

Ten antibiotics in ESI-MS were assigned to establish the fragmentation patterns. As a result, there was developed the data base of antibiotics that can be used for its rapid automatic identification of pharmaceutical formulation, biological and nature objects, based on comparison of characteristic ions. The results of the study showed that the proposed HPLC-MS method with ESI is simple, rapid, precise and accurate, which is useful for the routine identification of unknown antibiotics and determination ones in pharmaceutical formulation providing a high specificity.

\section{References}

[1] K. Benkenstock, Ph.D. Thesis, KTH, Royal Institute of Technology, Stockholm, Sweden 2008.

[2] M. Narayanam, T. Handa, P. Sharma, S. Jhajra, P.K. Muthe, P.K. Dappili, R.P. Shah, S. Singh, J. Pharmaceut. Biomed. Anal. 87, 191 (2014).

[3] E. Nägele, R. Moritz, J. Am. Soc. Mass Spectrom 16, 1670 (2005).

[4] G. Deng, G. Sanyal, J. Pharmaceut. Biomed. Anal. 40, 528 (2006).

[5] Xiao-Meng Chong, Chang-Qin Hu, Chromatographia 68, 759 (2008).

[6] R.F. Straub, R.D. Voyksner, J. Chromatography 647, 167 (1993).

[7] R. Nageswara Rao, N. Venkateswarlu, R. Narsimha, J. Chromatography A 1187, 151 (2008). 